\title{
The phenomenology of self-critical thinking in people with depression, eating disorders and in healthy individuals
}

\author{
Graham R Thew ${ }^{1}$, James Gregory ${ }^{1}$, Kate Roberts ${ }^{2}$, and Katharine Rimes ${ }^{3}$ \\ ${ }^{1}$ Department of Psychology, University of Bath, Claverton Down, Bath BA2 7AY, UK \\ ${ }^{2}$ B\&NES Primary Care Talking Therapies Service, Hillview Lodge, Royal United Hospital, \\ Combe Park, Bath, BA1 3NG, UK \\ ${ }^{3}$ Department of Psychology, Institute of Psychiatry, Psychology and Neuroscience, Kings \\ College London, London SE5 8AF, UK
}

Corresponding Author: Dr Katharine Rimes, Henry Wellcome Building, Department of Psychology, Institute of Psychiatry, Psychology and Neuroscience, Kings College London, De Crespigny Park, London SE5 8AF, UK

Email: Katharine.rimes@kcl.ac.uk

Phone: Tel. +44 (0)2078480430

Keywords: self-criticism; depression; anorexia nervosa; bulimia nervosa; perfectionism; 
PHENOMENOLOGY OF SELF-CRITICAL THINKING

\begin{abstract}
Objectives: To explore the phenomenology of self-criticism, and the relationship with constructs such as rumination and perfectionism.

Design: The study followed a three group (Depression, n=26; Eating Disorder, $n=26$; Nonclinical, $n=26$ ) mixed methods design.
\end{abstract}

Method: Participants completed a set of questionnaires and were interviewed about the occurrence, impact, and content of self-critical thinking, along with their beliefs about selfcriticism.

Results: Both clinical groups reported more frequent, persistent, and less controllable selfcriticism compared to controls, present on average $50-60 \%$ of the time. They reported a negative impact on mood, and a moderately severe impact on daily activities. They indicated greater desire to change self-criticism while judging it more difficult to reduce. Habitual selfcriticism was highly correlated with lower self-esteem, lower self-compassion, greater rumination and greater negative perfectionism. Compared to those with depression, the eating disorder group reported harsher self-criticism, felt it was more part of their personality, and was more beneficial.

Conclusions: The findings highlight the importance of exploring people's beliefs about their self-criticism, and imply that treatment for self-criticism may be more challenging with people with eating disorders than people with depression 


\section{PHENOMENOLOGY OF SELF-CRITICAL THINKING}

\section{Practitioner Points}

- The present study highlights that self-criticism is common in depression and eating disorders, and that some people find this a significant problem in its own right.

- Careful assessment of self-criticism is recommended when working with these clinical presentations, which should include the perceived positive consequences and desire to change. 
PHENOMENOLOGY OF SELF-CRITICAL THINKING

\section{Introduction}

Self-critical thinking has been described as a process of "harsh self-scrutiny and evaluation" (Blatt \& Zuroff, 1992, p. 528), and as "a conscious evaluation of oneself that can be a healthy and reflexive behaviour, but also can have harmful effects and consequences for an individual" (Kannan \& Levitt, 2013, p. 166). It has been identified as a feature of various mental health problems, including eating disorders (Fennig et al., 2008), social anxiety disorder (Cox et al., 2000), post-traumatic stress disorder (Cox, MacPherson, Enns, \& McWilliams, 2004) and depression (Luyten et al., 2007).

There is good evidence suggesting that self-criticism plays a role in the development and maintenance of psychological problems (Dunkley, Zuroff, \& Blankstein, 2006; Gilbert, Baldwin, Irons, Baccus, \& Palmer, 2006; Longe et al., 2010; see also Shahar, 2015), with self-criticism shown to mediate the relationship between shame and psychopathology, particularly where this takes the form of harsher and more self-attacking cognitions (Castilho, Pinto-Gouveia, \& Duarte, 2017; Duarte et al., 2017; Pinto-Gouveia, Castilho, Matos, \& Xavier, 2013). Work to develop interventions that specifically target self-critical thinking has been described in the literature (Falconer et al., 2014; Gilbert \& Procter, 2006; Shahar et al., 2012), though there remain aspects of self-criticism that are less well understood. Existing measures, such as the Forms and Functions of Self-Criticism scale (Gilbert, Clarke, Hempel, Miles, \& Irons, 2004), and the Depressive Experiences Questionnaire (Blatt, D'Afflitti, \& Quinlan, 1976) place more emphasis on stable, trait-based tendencies to think self-critically, or on assessing the broader aims of why people engage in self-critical thinking, or the nature of these cognitions (e.g. calling oneself names). Other aspects of self-critical phenomenology may therefore warrant further investigation, including the topics of selfcritical thoughts, the internal and external triggers that may elicit 'state' self-criticism, and its perceived emotional and functional impact. 


\section{PHENOMENOLOGY OF SELF-CRITICAL THINKING}

Another area that may benefit from further enquiry is evaluating how closely self-criticism relates to other cognitive processes or constructs. Self-criticism has commonly been studied as a component of perfectionism, being considered a process that occurs following a failure to meet one's own standards (Shafran, Cooper, \& Fairburn, 2002). There is evidence to suggest, however, that self-criticism may be an important determinant of when perfectionism becomes problematic and is not a key component of adaptive forms of perfectionism (Dunkley, Blankstein, Masheb, \& Grilo, 2006; Dunkley, Zuroff, et al., 2006; Gilbert, Durrant, \& McEwan, 2006). Similarly, improving our understanding of the strength of association between self-criticism and other constructs such as rumination and low self-esteem, and those thought to be inversely related to self-criticism such as self-compassion (Gilbert, Baldwin, et al., 2006), may help to clarify whether or how self-criticism is conceptually distinct.

Across three groups (depression, eating disorders, and nonclinical), this study aimed to explore the phenomenology and qualitative experience of self-critical thinking, and its associations with other cognitive constructs. While it was expected that most self-critical processes would occur similarly between the two clinical groups, we aimed to explore both similarities and differences to consider clinical implications.

It was hypothesised that self-critical thinking would show moderate-to-high correlations with negative perfectionism, rumination, lower self-compassion, low self-esteem and mood. We hypothesised that analyses would reveal themes common to both clinical conditions, as well as unique themes. It was predicted that participants with eating disorders would report higher levels of self-critical thoughts and triggers relating to eating, weight and shape than the other groups. However, in line with previous evidence of high levels of perfectionism being associated with depression and eating disorders, both clinical groups were predicted to report self-critical thoughts and triggers relating to achievement and performance. It was hypothesised that the clinical groups would report that their self-criticism was more frequent, 
PHENOMENOLOGY OF SELF-CRITICAL THINKING

less controllable, and had a greater negative impact than the healthy participants, and would have a greater desire to reduce their self-criticism.

\section{Method}

\section{Participants}

Recruitment and participation for this study was undertaken in conjunction with an experimental study (CITATION REMOVED FOR BLINDED REVIEW). A total of 78 participants were recruited across three groups: current major depressive disorder $(n=26), a$ current eating disorder $(n=26)$, and no current or historical mental health difficulties $(n=26)$. Twelve of the eating disorder group participants also had comorbid depression (see CITATION REMOVED FOR BLINDED REVIEW). Diagnostic status was assessed using the Mini International Neuropsychiatric Interview (MINI; Sheehan et al., 1998). Mean depression and eating disorder severity scores are reported in Table 1.

Clinical participants were identified by treating clinicians in local mental health services and through community advertisements. Control group participants were recruited primarily from university student and staff populations and the local community. All participants met group inclusion criteria and were aged 18 or over. Exclusion criteria were high levels of risk (identified by clinician), or difficulties with written/spoken English. Participants were reimbursed for their time using vouchers or, where relevant, course credit. The study was approved by the National Research Ethics Committee (Study reference 13/WA/0158).

\section{Design}

The study followed a three-group (current depression, current eating disorder, no history of mental health problems) cross-sectional design. These groups were chosen to enable the investigation of clinical versus nonclinical differences in self-critical thinking, alongside exploring both disorder-specific and transdiagnostic aspects through comparison of the clinical groups. Consequently, a mixed-methods approach was used employing a range of 
PHENOMENOLOGY OF SELF-CRITICAL THINKING

questionnaire measures and an interview incorporating both structured and semi-structured elements.

\section{Materials}

\section{Standardised Questionnaires.}

\section{Self-criticism:}

- Habit Index of Negative Thinking (HINT; Verplanken, Friborg, Wang, Trafimow, \& Woolf, 2007). A measure of habitual self-critical thinking, the HINT was used to explore the cognitive process element of self-criticism. It has good psychometric properties (Verplanken et al., 2007) and internal consistency; Cronbach's alpha in this study was 0.97 .

- Forms of Self-Criticizing/attacking and reassurance scale (FSCRS) and Functions of Self-Criticizing/attacking scale (FSCS) (Gilbert et al., 2004). These scales were chosen due to their wide use in the assessment of self-criticism. The FSCRS contains subscales of 'Inadequate self', 'Hated self', and 'Reassured self' and was scored according to Kupeli, Chilcot, Schmidt, Campbell, and Troop (2013). The FSCS contains subscales of self-correction and self-persecution. Cronbach's alpha coefficients were 0.95 and 0.94 respectively.

Perfectionism:

- Frost Multidimensional Perfectionism Scale (MPS; Frost, Marten, Lahart, \& Rosenblate, 1990). One of the most commonly used measures of perfectionism, analyses used the MPS Negative Perfectionism subscale, which is computed as the total of the following subscales: Concern over Mistakes, Doubting of Actions, Parental Expectations, and Parental Criticism (see Frost, Heimberg, Holt, Mattia, \& Neubauer, 1993). Cronbach's alpha in this study was 0.94 .

Depression symptoms: 
- Centre for Epidemiological Studies Depression Scale (CES-D; Radloff, 1977). The CES-D is a widely used and validated brief measure of depression symptoms (see Weissman, Sholomskas, Pottenger, Prusoff, \& Locke, 1977). It was chosen due to its frequent use and limited amount of cognitive item content. Cronbach's alpha in this study was 0.93 .

Eating Disorder symptoms:

- Eating Disorder Examination Questionnaire (EDE-Q; Fairburn \& Beglin, 2008). Chosen as a general measure of self-reported eating disorder symptoms, the present study used the global scale of the EDE-Q, which averages the four subscales of Restraint, Eating Concern, Weight Concern, and Shape Concern. Cronbach's alpha was 0.96 .

Self-esteem:

- Rosenberg Self-Esteem Scale (RSE; Rosenberg, 1986). This scale is the most widely-used measure of global self-esteem, with good psychometric properties (see Gray-Little, Williams, \& Hancock, 1997). Cronbach's alpha in this study was 0.90 .

Rumination:

- Rumination-Reflection Questionnaire (RRQ; Trapnell \& Campbell, 1999). The rumination items were used (see Trapnell \& Campbell, 1999) as a global indicator of negatively-valenced ruminative thought; Cronbach's alpha in this study was 0.92 .

Self-compassion:

- Self-compassion scale Short Form (SCS; Raes, Pommier, Neff, \& Van Gucht, 2011). A brief scale producing a global measure of self-compassion, the SCS was used to examine a potential inverse relationship with self-criticism.

Cronbach's alpha in the current study was 0.89 .

Functioning with respect to self-critical thinking: 
- Work and Social Adjustment Scale (WSAS; Mundt, Marks, Shear, \& Greist, 2002). The WSAS examines the functional impact of a particular problem defined by the researcher; self-critical thinking was therefore used in the current study and Cronbach's alpha was 0.91 .

\section{Self-criticism Interview.}

An audio-recorded interview was undertaken after the questionnaires to explore people's experiences of self-critical thinking. The interview schedule comprised questions developed on an a priori basis based on the components of cognitive behavioural models (cf. Beck, Rush, Shaw, \& Emery, 1979) to explore the phenomenology of self-critical thinking. It contained three elements, outlined below:

\section{Overview of occurrence and impact of self-criticism.}

A range of both specific (closed) and more exploratory (open) questions covering the following were included: presence, frequency, topics, and duration of self-criticism, internal and external triggers, the presence of deliberate self-criticism, management strategies, positive and negative consequences, chronicity and beliefs about onset, and the desire and possible methods to change self-criticism.

\section{Self-critical content.}

As existing measures of self-criticism do not specifically explore which aspects of the self people tend to criticise, participants completed an original brief questionnaire about the content and frequency of self-critical thoughts in the past week. Twenty-seven potential selfcritical topics (such as 'my intelligence', 'how successful I am', or 'my relationships with friends') were included based on existing literature and the authors' clinical experience. Participants rated each one on a 1-6 scale (with response options of 'never', 'occasionally', 'several times a week', 'most days', 'many times a day', and 'most or all of the time'). This questionnaire also asked for an estimate of the percentage of time spent thinking self- 


\section{PHENOMENOLOGY OF SELF-CRITICAL THINKING}

critically on a typical day. It was administered following discussion of self-critical topics as part of the interview.

\section{Beliefs about self-criticism.}

To assess beliefs about self-criticism, participants were asked to provide Likert scale ratings of the amount of perceived control they have over self-critical thinking ("On a scale from 0 to 10 where 0 is not at all controllable and 10 being totally controllable, how would you view self-critical thinking?"), the desire to make changes to their self-critical thinking ("Would you like to change anything about your self-critical thinking?", using a 0-10 scale where 0 is 'I wouldn't change anything' and 10 'I want to change everything about my self-critical thinking'), and agreement with the following statements: self-critical thinking has benefits for me; self-critical thinking has disadvantages for me; I would like to reduce my self-criticism; being self-critical is part of my personality; my self-criticism is a learnt habit that could be unlearnt; it would be difficult to reduce my self-criticism; I would be interested in advice about how to reduce my self-criticism. These statements were rated verbally on a 1-7 Likert scale, with labels of 'totally agree', 'agree very much', 'agree slightly', 'neutral', 'disagree slightly', 'disagree very much', and 'totally disagree', respectively. Lower scores thus indicated greater agreement. They were administered at the relevant point within the interview, to obtain a summary score of their views having just discussed the topic.

\section{Analysis}

Responses to the standardised questionnaires were analysed to compare responses between groups, and using a single sample design to explore relationships between the measures. Analytic assumptions and outliers were examined prior to analysis, and no transformations or exclusions were indicated.

For the interview, the analysis of participants' responses to the open questions followed a procedure based on framework analysis (Gale, Heath, Cameron, Rashid, \& Redwood, 


\section{PHENOMENOLOGY OF SELF-CRITICAL THINKING}

2013), a process suited for the analysis of qualitative data that is based on more specific questions and pre-designed samples (Srivastava \& Thomson, 2009). Responses were reviewed by the first author (a clinical psychologist), with each question treated as a category within the framework. A set of codes for each category was developed iteratively based on the raw data, and these were then used to form a summary matrix. Interpretation involved reviewing the frequency of codes within each category, comparing these across the three groups to explore thematic similarities and differences in participants' responses to each question. Samples of audio-recordings were reviewed and coded by two independent raters to ensure the reliability of the procedure, which found good consistency of coding choices between rater pairs $(85-96 \%)$.

All closed questions and Likert scale responses to interview questions were analysed descriptively, as were responses to the questionnaire on self-critical content and frequency.

\section{Results}

\section{Standardised questionnaires}

One-way analyses of variance (ANOVA) were used to compare the scores of the three groups on the questionnaires. The two clinical groups showed higher ratings of self-criticism, negative perfectionism, depression symptoms, functional impairment from self-criticism, rumination, and items of the inadequate self FSCRS subscale compared to controls. The clinical groups had lower scores relative to the control group for self-esteem, selfcompassion, and the FSCRS reassured self subscale. Overall, the two clinical groups generally differed from controls but not from each other. The only differences found between the two clinical groups were for the hated self FSCRS subscale, the self-persecution FSCS subscale, and eating disorder symptoms, where the eating disorder group showed higher scores compared to the depression group (see Table 1.).

[TABLE 1 ABOUT HERE] 


\section{Association between self-critical thinking, related constructs, and depressive symptoms}

Pearson correlations were conducted to investigate the strength of association between scores on the questionnaires, analysing all participants together (see Table 2.). As expected, there were significant moderate-to-high correlations between all of the measures.

\section{[TABLE 2 ABOUT HERE]}

\section{Participant interviews}

Presence, frequency, and duration.

All participants reported experiencing self-critical thoughts, though there was a marked difference between the groups regarding their frequency. While the control group most commonly reported them occurring a few times a week, the majority of the two clinical groups reported their frequency to be multiple times per day. Regarding duration, control group participants tended to report only brief instances, with the clinical groups experiencing much longer lasting episodes:

"A few seconds, I don't dwell on it too much" (Participant 4, control group)

"If I've had an argument or feel I've upset someone, then [the self-criticism] could go on for days" (Participant 34, depression group)

"[It's] like a constant hum in the background and occasionally the noise gets turned up" (Participant 69, eating disorder group)

Forty participants reported that the duration of self-criticism was variable depending on other factors, namely the topic of the thought (17 participants), their level of activity at the time (14 participants), mood (eight participants), or tiredness (one participant).

\section{Triggers.}




\section{PHENOMENOLOGY OF SELF-CRITICAL THINKING}

The external trigger most frequently reported by the control and depression groups was making a mistake or failing at something (ten and seven participants respectively), and this trigger was also relatively common in the eating disorder group (seven participants):

"If I've burnt the dinner or something stupid like that, or like this morning we were late for school..." (Participant 31, depression group)

External triggers most commonly mentioned by the eating disorder group included: being in social situations or with friends (12 participants); mealtimes or eating (11 participants); seeing other people they perceive as ideal regarding appearance, achievement, or competence (ten participants); being in the work/college environment (eight participants); and noticing things in the environment that remind them of their self-critical topics (seven participants):

"If I'm just on social networking sites like Facebook and pictures pop up of people, then I'm instinctively quite [self] critical" (Participant 70, eating disorder group)

Other external triggers mentioned by at least one person in each group included: waking up or early mornings; evenings or trying to sleep; hangovers; mirrors or seeing your reflection; actual or perceived criticism from others; external pressures and stress; social conflict and arguments; uncertainty or things not going to plan; being alone; and being with family members.

Regarding internal triggers, feeling low in mood was reported frequently in all three groups, being mentioned by $62 \%, 77 \%$, and $73 \%$ of the control, depression and eating disorder groups respectively. It was, however, noted by some participants that the relationship between mood and self-critical thinking is not always clear:

"I'm not sure whether it's the mood that affects the thinking, or whether it's the thinking that triggers the mood off, and I can't sort that out in my mind." (Participant 32 , depression group) 
Other themes regarding internal triggers were also similar across groups, such as: thinking about particular topics (past mistakes/failures, relationships with others, or the future); anxiety or worry; tiredness; or feeling a lack of achievement/productivity.

When asked whether it was more common for self-critical thoughts to be brought on by external or internal triggers, group differences were present, with $95 \%$ of the control group, and $61 \%$ of the depression group stating external triggers, and $61 \%$ of the eating disorder group stating internal triggers to be more common.

\section{Control and management.}

Only three participants described seeing self-critical thinking as a predominantly deliberate process, all of whom were in the control group. Overall participants described feeling they have little control over the occurrence of self-critical thoughts, estimating that $85 \%$ would arise automatically, and $15 \%$ brought on more deliberately. This did not vary markedly between groups.

The percentages of each group who stated that they engage in deliberate self-criticism was $46 \%$ of the control group, $35 \%$ of the depression group, and $58 \%$ of the eating disorder group. A theme within the control group was that this was done for reasons of selfimprovement:

"Occasionally I will [bring on self-critical thoughts] at work to analyse how I could do something better...or work with somebody better" (Participant 15, control group)

This was less common in the two clinical groups, with deliberate self-criticism being more commonly reported following a mistake, or for reasons of self-punishment. In the eating disorder group, there was also a theme of using deliberate self-criticism in response to, or in order to neutralise, a positive thought: 
PHENOMENOLOGY OF SELF-CRITICAL THINKING

"I think it's a kind of punishment type thing, if I feel good or happy about something then I would make myself feel bad by thinking bad thoughts...in some ways it feels like tempting fate to be happy or think something good." (Participant 55, eating disorder group)

In all groups, the most commonly reported area of perceived control over self-critical thinking was in how participants respond to thoughts when they arise. These responses included using distraction; applying logic/reason to evaluate the thought; dismissing or "boxing it away'; choosing to think or do something else; and trying to use the thought for positive action:

"If I can step back and see it from a distance, I can usually see exactly what it is that is causing the problem...then the answer kind of follows." (Participant 16, control group)

"If I make the effort [with my appearance] I can make myself feel better." (Participant 42, depression group)

The most frequently reported strategy for managing self-critical thoughts was through distraction or keeping busy, and this was reported by $73 \%, 50 \%$, and $81 \%$ of the control, depression, and eating disorder groups respectively. Nine participants in the control group mentioned the value of seeking help and support from others, whereas this was much less frequent in the clinical groups. The strategy of evaluating or analysing the self-critical thought was more common in the clinical groups (nine participants in each):

"I can rationalise things, like if I'm late it's not always because it's my fault - I can't control traffic" (Participant 65, eating disorder group)

Other strategies mentioned at least once in all groups included: suppression or pushing away of thoughts; self-talk; focusing on positives; changing your environment; being selfcompassionate; and attempting to avoid triggers by withdrawing. 


\section{Effects and impact.}

Regarding positive effects, two main themes were identified across all groups, namely a beneficial effect on motivation and drive (11 control group, five depression group, and 14 eating disorder group participants), and the potential for self-improvement (14 control group, five depression group, and six eating disorder group participants):

"It keeps you motivated - when I get self-critical I tend not to stay in that state but try to get out of it and I work harder" (Participant 17, control group)

"It's an evaluation process - it can highlight things that you want to work on on yourself" (Participant 49, depression group)

A theme arising only in the control group (ten participants) was that self-criticism can help you learn better from your mistakes. Secondary themes occurring more often in the clinical groups than the control group were the role of self-criticism in leading to higher achievements and productivity, and in preventing arrogance:

"It means the quality of my work is very high, and that is an advantage to my employers, but I...could probably afford to produce work of a slightly lower quality and still do a good job...l often receive good feedback about the quality of my work." (Participant 58, eating disorder group)

"You can't go through life thinking you're wonderful all the time" (Participant 30, depression group)

The main negative effect identified was the lowering of mood (16 control group, 24 depression group, and 24 eating disorder group participants). A negative impact on activities, in particular doing less, was also frequently reported (15 depression group, and 13 eating disorder group participants) but not by the control group. 
PHENOMENOLOGY OF SELF-CRITICAL THINKING

"I don't feel that I can do anything - my friends [say] 'why don't you go and do a new course?', and I'm like 'well no, why would I go and do that'? It limits what you believe you can do" (Participant 39, depression group)

Other negative effects mentioned in all groups were: anger/frustration; isolating or withdrawing self from others; reduced self-esteem; reduced confidence; further self-critical thoughts; negative impact on relationships; reduced achievement/productivity; tiredness or fatigue; reduced pleasure; reduced motivation; rumination; impaired concentration/memory; and anxiety. Self-harm and food restriction or bingeing were also reported, with this being more common in the eating disorder group.

When asked whether they saw self-criticism as mainly positive or mainly negative, $65 \%$ of the control group reported it was positive:

"I think it's quite helpful for your inner voice to say... [e.g.] 'that wasn't very nice what you just said to that person, no excuses, I don't care that you're upset or what have you, go back and say sorry'...I think that's a perfectly healthy response" (Participant 12 , control group)

In contrast, $96 \%$ and $91 \%$ of the depression and eating disorder groups respectively felt it was negative overall:

"It's had a devastating impact on my life" (Participant 32, depression group)

"It makes life very hard, it's very tiring having that going on in your head - sometimes I wish I could just take my head off and have a breather...it just takes all the sparkle out of things." (Participant 53, eating disorder group)

\section{Onset and development.}

Participants were asked if they had a specific early memory of an event or situation in which they remember feeling particularly self-critical. Such memories were reported in $15 \%$ of the 


\section{PHENOMENOLOGY OF SELF-CRITICAL THINKING}

control group, $35 \%$ of the depression group, and $46 \%$ of the eating disorder group. Where age at the time was reported, the mean age at which these events occurred was 7 years (range 3-14.5). These events generally involved feelings of shame or humiliation, some being internally generated, and some in response to bullying or criticism from parents, relatives or teachers. In the eating disorder group these events were more frequently, but not exclusively, linked to appearance or body shape/size.

There were two main themes reported as to how self-criticism developed initially: that it is an innate tendency or fixed trait (14 control group, ten depression group, and 12 eating disorder group participants); or that it was learnt from others' self-criticism or direct criticism (ten control group, 15 depression group, and five eating disorder group participants):

"It seems to me like a personality trait, it's more just a part of me really, just something I do" (Participant 20, control group)

"My father was extremely critical, I was very criticised so the seeds were there from childhood" (Participant 47, depression group)

Secondary themes included high family standards or expectations (six control group, five depression group, and eight eating disorder group participants), and a triggering event or trauma (six depression group, and 4 eating disorder group participants, but none of the control group):

“I felt like I never lived up to my parents' expectations" (Participant 76, eating disorder group)

The principal theme regarding why self-criticism continues was that it has become habitual or routine (eight control group, eight depression group, and six eating disorder group participants): 
PHENOMENOLOGY OF SELF-CRITICAL THINKING

"I think there's an element of mental laziness about resorting to self-criticism sometimes it's harder to be confident and it's easier to just use self-criticism as a default" (Participant 58, eating disorder group)

Similarly to some participants' responses regarding onset, there was also a theme of selfcriticism continuing because it is 'part of who I am' (four control group, seven depression group, and four eating disorder group participants). Four depression group and five eating disorder group participants reported that continuation was due to not addressing the areas they are critical about; this was not mentioned in the control group:

"I never changed anything, so unless you change something to change your behaviour, nothing's going to be different is it?" (Participant 78, eating disorder group)

\section{Making changes.}

While some participants in each group reported they wished to change the topic (eight control group, four depression group, and seven eating disorder group participants), and reduce the frequency (seven control group, four depression group, and five eating disorder group participants) of self-critical thoughts, it was the clinical groups that reported a desire to reduce their emotional impact (one control group, nine depression group, and 13 eating disorder group participants), and their strength/intensity (one control group, five depression group, and seven eating disorder group participants):

"It would be good if it didn't affect my mood so much, if it was easier to control...so if I have a thought which snowballs...it would be good to be able to put a stop to that and prevent it from really affecting how I feel." (Participant 52, depression group)

Whilst nearly all participants thought that it would be possible to change self-critical thoughts to some extent, there was a theme within all groups that this would be hard to do, with the eating disorder group feeling this would be especially difficult: 
PHENOMENOLOGY OF SELF-CRITICAL THINKING

"I've been trying for years...I think it's incredibly hard, really hard" (Participant 53, eating disorder group)

Participants outlined a range of potential strategies they felt could be helpful to support them or others with making changes to self-critical thinking. The two main themes in the control group were accessing social support (seven participants) and addressing the areas one is self-critical about (nine participants). Themes highlighted by the depression and eating disorder groups included accessing therapy (such as cognitive behaviour therapy and mindfulness; ten and five participants respectively), and trying to reframe or analyse the thoughts in a controlled way (eight and five participants respectively).

"Sometimes it takes someone removed from the situation to be able to say to you 'why are you saying/thinking that?'... It's opening up and seeing it from someone else's perspective that can start you thinking in a more... I don't know whether it's... rational way, but that's definitely helped me in the past." (Participant 29, depression group)

"It would have to be something very structured that I could cling to I think... I suppose that sort of reflection on what you think...halting [the self-critical process], thinking 'no wait, that's silly, you don't know that...you're ok'” (Participant 51, depression group)

Other themes within the clinical groups included: increasing meaningful activity; increasing kindness and compassion towards the self; medication; exercise; and focusing on a goal or target.

\section{Content and frequency questionnaire}

The depression group had on average experienced most self-critical thoughts about their $\operatorname{mood}(M=4.73, S D=1.31)$, feelings $(M=4.54, S D=1.42)$, and future $(M=4.54, S D=1.58)$. For the eating disorder group the most common topics were their eating $(M=5.38, S D=$ 1.06), weight or body shape $(M=5.15, S D=1.35)$, and appearance $(M=5.08, S D=1.23)$. 
PHENOMENOLOGY OF SELF-CRITICAL THINKING

Aside from eating disorder-related topics, the most common topics were their feelings $(M=4.46, S D=1.56), \operatorname{mood}(M=4.42, S D=1.47)$, and thoughts $(M=4.38, S D=1.39)$. The control group reported less frequent self-critical thoughts; the most common topics were their appearance $(M=2.62, S D=1.33)$, weight or body shape $(M=2.58, S D=1.21)$, and physical fitness $(M=2.58, S D=1.14)$.

Participants' estimates of the percentage of time they spent thinking self-critically on a typical day showed a significant difference between groups: $F(2,73)=35.0, p<.001$. Post-hoc Tukey comparisons showed that both the depression $(M=48.5, S D=28.5)$, and eating disorder $(M=59.2, S D=23.6)$ groups gave significantly higher ratings compared to the control group $(M=9.8, S D=9.4)$. The two clinical groups were not significantly different.

\section{Beliefs about self-critical thinking}

One-way ANOVAs were used to compare the three groups' beliefs about self-critical thinking. The two clinical groups rated their self-criticism as being less controllable and more disadvantageous compared to controls, and reported greater desire to reduce it, and greater interest in receiving advice about how to reduce it. While they showed greater agreement relative to controls that self-criticism is a learnt habit, they also believed it would be more difficult to reduce. Compared to the depression group, the eating disorder group showed less desire to change their self-critical thinking, felt it was more beneficial, and more personalitybased (see Table 3.).

\section{[TABLE 3 ABOUT HERE]}

\section{Discussion}

This study aimed to explore the phenomenology of critical thinking and its relationship to other cognitive constructs. Self-critical thinking as measured by the HINT was highly correlated with greater depression, perfectionism, rumination and lower self-compassion, 
with the largest (inverse) association being with self-esteem. This suggests that a global negative attitude towards oneself and habitual, automatic and frequent self-critical thinking typically co-occur. The results are consistent with previous findings showing a relationship between self-criticism and psychological difficulties (Dunkley, Blankstein, et al., 2006; Dunkley, Zuroff, et al., 2006), and an inverse relationship between self-critical thinking and self-compassion (James, Verplanken, \& Rimes, 2015). The high correlations between most constructs assessed could suggest that the measures used show limited specificity, and instead may be assessing broader underlying constructs such as negative cognition, repetitive/habitual thinking, or low mood. A common dilemma in working therapeutically with depression and other presentations, is determining which cognitive maintaining processes would most usefully be targeted. The present findings regarding the interrelationships between cognitive constructs in depression and eating disorders suggest that focusing on one could have a positive effect upon the others.

Early memories linked to shame or humiliation appeared to be a sufficient but not necessary condition for developing later self-criticism, consistent with some mediation findings (PintoGouveia et al., 2013), though there is a potential for retrospective bias in participants' responses. Themes around onset did not show strong differences between groups, though the eating disorder group were more likely to see self-criticism as part of their personality than the other groups, who were more likely to report that self-criticism was externally triggered, for example by failure events. The most commonly mentioned external trigger in the eating disorder group was social situations rather than eating. This may reflect a high degree of social comparison and fear of negative evaluation in people with eating disorders (see Corning, Krumm, \& Smitham, 2006). This perhaps triggers feelings of shame, which has been found to mediate the self-criticism-eating disorder pathology relationship (Kelly \& Carter, 2013). All clinical participants and most nonclinical participants described the predominantly automatic and habitual nature of self-criticism, suggesting it may not always 
PHENOMENOLOGY OF SELF-CRITICAL THINKING

be a conscious action, which is at odds some existing definitions of self-criticism, such as Kannan and Levitt (2013).

As predicted, the clinical groups reported more, and longer-lasting self-critical thoughts than the control group, and rated themselves lower in self-compassion. This is consistent with work suggesting that lower self-compassion, and greater fear of compassion plays a role in clinical symptomatology (Gilbert, McEwan, Catarino, \& Baião, 2014; Gilbert et al., 2012; Kelly, Carter, Zuroff, \& Borairi, 2013). Clinical participants estimated they were experiencing self-critical thoughts around $50-60 \%$ of the time on average. Also as expected, the eating disorder group reported that their most common self-critical thoughts were about shape, weight, eating, and appearance. This suggests there may be condition-specific self-critical content. The eating disorder group also described frequent self-critical thoughts about their mood and feelings, which was also common in the depression group. However, since comorbid depression was common in the eating disorder group, it is not possible to draw conclusions about whether this was a transdiagnostic aspect of self-criticism. Further research is needed with people with eating disorders without comorbid depression to address this issue.

Participants noted both positive (motivation, self-improvement), and negative (low mood, reduced activity) emotional and behavioural consequences of self-criticism. However, while the majority of the control group felt it was positive overall, nearly all clinical participants felt it was negative, reporting little control over the process. These findings support the further investigation and evaluation of self-criticism as a treatment focus in its own right (see Falconer et al., 2014; Gilbert \& Procter, 2006; Shahar et al., 2012). Indeed, both clinical groups gave high ratings for interest in help to reduce their self-criticism.

Considering participants' beliefs about self-criticism, the eating disorder group rated it as more beneficial compared to the other groups and had less desire to change, consistent with 
the complex and ambivalent relationship with the 'anorexic voice' described in Tierney and Fox (2010). Combined with the behavioural pattern of more frequent deliberate self-criticism in this group, it is likely that self-criticism will be particularly difficult to treat in people with eating disorders, and that understanding how people perceive their own self-criticism may be important clinically.

The questionnaire and interview findings are broadly complementary. For example, both clinical groups reported ways in which self-criticism can restrict their activities and negatively affect relationships, which is consistent with scores on the WSAS, which indicated a moderately severe functional impairment associated with self-criticism. Although in most respects the two clinical groups showed similar experiences of self-criticism, the way the interview responses of participants in the eating disorder group differed from the depression group was also mirrored in some questionnaire responses. They were more likely to report self-correction as a function of their self-criticism, and showed higher scores on the 'Hated Self' FSCRS subscale, and the self-persecution FSCS subscale. Overall this indicates that self-criticism may be particularly deliberate, self-attacking, and punitive in the context of eating disorders, in line with studies showing that eating disorder pathology is exacerbated by high self-criticism (Kelly \& Carter, 2013).

Study limitations include the use of self-report measurement and introspection on cognitive processes, which may be even more difficult when currently experiencing mental health difficulties. However, as most self-criticism is internal, observer ratings would have only limited validity. There was some comorbid depression in the eating disorder group, as is common in this population, which may limit the independence of the clinical groups.

Researchers have criticised the SCS for its inclusion of self-criticism items, and thus poor validity (Costa, Marôco, Pinto-Gouveia, Ferreira, \& Castilho, 2015; López et al., 2015; Muris, 2016). Although its psychometric properties have recently been defended by the original author (Neff, 2016), present findings in relation to this scale should be interpreted cautiously. 
Finally, the content and frequency questionnaire was developed specifically for this study so would require broader factor analytic work to assess its psychometric properties.

These findings suggest a number of clinical implications, the broadest being a need to remain alert to the presence and impact of self-criticism across assessments and interventions. As self-critical thinking is often perceived as automatic, part of one's personality, and difficult to control, clients may not present requesting treatment for this process. The positive beliefs about self-criticism expressed here suggest these would be important to review clinically, particularly in eating disorders, where the self-critical 'voice' can be seen as motivating and friendly (Tierney \& Fox, 2010). Addressing positive beliefs about self-criticism may help to improve the likelihood of progress. It is noted that a number of coping strategies mentioned here might be considered maladaptive, or have the unintended effect of maintaining problems, so exploring this would be beneficial. Lastly it is noted that excessive self-critical thinking was considered by some participants to be just as significant a problem as depression or an eating disorder, again suggesting it may be appropriate in some instances for this to form the focus of intervention. Indeed, a number of compassion-focused interventions have been developed that specifically target self-critical thinking (see Kirby, 2016; Leaviss \& Uttley, 2015).

This study has highlighted the high frequency of self-critical thoughts among people experiencing depression and eating disorders, along with the significant impairment they can cause in their own right. This suggests a need for the continued development and evaluation of treatments to target self-critical thinking. The eating disorder group participants described more benefits of self-criticism, and less desire to change their self-criticism compared to the depression group, which suggests addressing this in treatment may be more challenging in this population. 


\section{References}

Beck, A., Rush, A., Shaw, B., \& Emery, G. (1979). Cognitive Therapy of Depression. New York: Guilford Press.

Blatt, S. J., D'Afflitti, J. P., \& Quinlan, D. M. (1976). Experiences of depression in normal young adults. Journal of Abnormal Psychology, 85(4), 383-389.

Blatt, S. J., \& Zuroff, D. C. (1992). Interpersonal relatedness and self-definition: Two prototypes for depression. Clinical psychology review, 12(5), 527-562.

Castilho, P., Pinto-Gouveia, J., \& Duarte, J. (2017). Two forms of self-criticism mediate differently the shame-psychopathological symptoms link. Psychology and Psychotherapy: Theory, Research and Practice, 90(1), 44-54. doi:10.1111/papt.12094

Costa, J., Marôco, J., Pinto-Gouveia, J., Ferreira, C., \& Castilho, P. (2015). Validation of the psychometric properties of the self-compassion scale. Testing the factorial validity and factorial invariance of the measure among borderline personality disorder, anxiety disorder, eating disorder and general populations. Clinical Psychology \& Psychotherapy, 23(5), 460-468. doi:10.1002/cpp.1974

Cox, B. J., MacPherson, P. S. R., Enns, M. W., \& McWilliams, L. A. (2004). Neuroticism and self-criticism associated with posttraumatic stress disorder in a nationally representative sample. Behaviour Research and Therapy, 42(1), 105-114.

Cox, B. J., Rector, N. A., Bagby, R. M., Swinson, R. P., Levitt, A. J., \& Joffe, R. T. (2000). Is self-criticism unique for depression? A comparison with social phobia. Journal of Affective Disorders, 57(1-3), 223-228.

Duarte, C., Matos, M., Stubbs, R. J., Gale, C., Morris, L., Gouveia, J. P., \& Gilbert, P. (2017). The impact of shame, self-criticism and social rank on eating behaviours in overweight and obese women participating in a weight management programme. PloS One, 12(1), e0167571. doi:https://doi.org/10.1371/journal.pone.0167571

Dunkley, D. M., Blankstein, K. R., Masheb, R. M., \& Grilo, C. M. (2006). Personal standards and evaluative concerns dimensions of "clinical" perfectionism: A reply to Shafran et al. (2002, 2003) and Hewitt et al. (2003). Behaviour Research and Therapy, 44(1), 63-84. doi:http://dx.doi.org/10.1016/j.brat.2004.12.004

Dunkley, D. M., Zuroff, D. C., \& Blankstein, K. R. (2006). Specific perfectionism components versus self-criticism in predicting maladjustment. Personality and Individual Differences, 40(4), 665-676.

Fairburn, C. G., \& Beglin, S. (2008). Eating Disorder Examination Questionnaire. In C. G. Fairburn (Ed.), Cognitive Behaviour Therapy and Eating Disorders. New York: Guildford Press.

Falconer, C. J., Slater, M., Rovira, A., King, J. A., Gilbert, P., Antley, A., \& Brewin, C. R. (2014). Embodying compassion: A virtual reality paradigm for overcoming excessive self-criticism. PloS One, 9(11), e111933. doi:10.1371/journal.pone.0111933

Fennig, S., Hadas, A., Itzhaky, L., Roe, D., Apter, A., \& Shahar, G. (2008). Self-criticism is a key predictor of eating disorder dimensions among inpatient adolescent females. International Journal of Eating Disorders, 41(8), 762-765.

Frost, R. O., Heimberg, R. G., Holt, C. S., Mattia, J. I., \& Neubauer, A. L. (1993). A comparison of two measures of perfectionism. Personality and Individual Differences, 14(1), 119-126.

Frost, R. O., Marten, P., Lahart, C., \& Rosenblate, R. (1990). The dimensions of perfectionism. Cognitive Therapy and Research, 14(5), 449-468.

Gale, N. K., Heath, G., Cameron, E., Rashid, S., \& Redwood, S. (2013). Using the framework method for the analysis of qualitative data in multi-disciplinary health research. BMC medical research methodology, 13(1), 117. 
Gilbert, P., Baldwin, M. W., Irons, C., Baccus, J. R., \& Palmer, M. (2006). Self-criticism and self-warmth: An imagery study exploring their relation to depression. Journal of Cognitive Psychotherapy, 20(2), 183-200. doi:https://doi.org/10.1891/jcop.20.2.183

Gilbert, P., Clarke, M., Hempel, S., Miles, J., \& Irons, C. (2004). Criticizing and reassuring oneself: An exploration of forms, styles and reasons in female students. British Journal of Clinical Psychology, 43(1), 31-50.

Gilbert, P., Durrant, R., \& McEwan, K. (2006). Investigating relationships between perfectionism, forms and functions of self-criticism, and sensitivity to put-down. Personality and Individual Differences, 41(7), 1299-1308. doi:10.1016/j.paid.2006.05.004

Gilbert, P., McEwan, K., Catarino, F., \& Baião, R. (2014). Fears of compassion in a depressed population: Implications for psychotherapy. Journal of Depression and Anxiety, S2: 003. doi:10.4172/2167-1044.S2-003

Gilbert, P., McEwan, K., Gibbons, L., Chotai, S., Duarte, J., \& Matos, M. (2012). Fears of compassion and happiness in relation to alexithymia, mindfulness, and self-criticism. Psychology and Psychotherapy: Theory, Research and Practice, 85(4), 374-390. doi:10.1111/j.2044-8341.2011.02046.x

Gilbert, P., \& Procter, S. (2006). Compassionate mind training for people with high shame and self-criticism: Overview and pilot study of a group therapy approach. Clinical Psychology \& Psychotherapy, 13(6), 353-379. doi:10.1002/cpp.507

Gray-Little, B., Williams, V. S., \& Hancock, T. D. (1997). An item response theory analysis of the Rosenberg Self-Esteem Scale. Personality and Social Psychology Bulletin, 23(5), 443-451.

James, K., Verplanken, B., \& Rimes, K. A. (2015). Self-criticism as a mediator in the relationship between unhealthy perfectionism and distress. Personality and Individual Differences, 79, 123-128.

Kannan, D., \& Levitt, H. M. (2013). A review of client self-criticism in psychotherapy. Journal of Psychotherapy Integration, 23(2), 166-178.

Kelly, A. C., \& Carter, J. C. (2013). Why self-critical patients present with more severe eating disorder pathology: The mediating role of shame. British Journal of Clinical Psychology, 52(2), 148-161. doi:10.1111/bjc.12006

Kelly, A. C., Carter, J. C., Zuroff, D. C., \& Borairi, S. (2013). Self-compassion and fear of self-compassion interact to predict response to eating disorders treatment: A preliminary investigation. Psychotherapy Research, 23(3), 252-264. doi:http://dx.doi.org/10.1080/10503307.2012.717310

Kirby, J. N. (2016). Compassion interventions: The programmes, the evidence, and implications for research and practice. Psychology and Psychotherapy: Theory, Research and Practice. doi:10.1111/papt.12104

Kupeli, N., Chilcot, J., Schmidt, U. H., Campbell, I. C., \& Troop, N. A. (2013). A confirmatory factor analysis and validation of the forms of self-criticism/reassurance scale. British Journal of Clinical Psychology, 52, 12-25.

Leaviss, J., \& Uttley, L. (2015). Psychotherapeutic benefits of compassion-focused therapy: An early systematic review. Psychological Medicine, 45(05), 927-945. doi:10.1017/S0033291714002141

Longe, O., Maratos, F. A., Gilbert, P., Evans, G., Volker, F., Rockliff, H., \& Rippon, G. (2010). Having a word with yourself: Neural correlates of self-criticism and selfreassurance. NeuroImage, 49(2), 1849-1856. doi:http://dx.doi.org/10.1016/j.neuroimage.2009.09.019

López, A., Sanderman, R., Smink, A., Zhang, Y., van Sonderen, E., Ranchor, A., \& Schroevers, M. J. (2015). A reconsideration of the Self-Compassion Scale's total 
score: Self-compassion versus self-criticism. PloS One, 10(7), e0132940. doi:https://doi.org/10.1371/journal.pone.0132940

Luyten, P., Sabbe, B., Blatt, S. J., Meganck, S., Jansen, B., De Grave, C., . . Corveleyn, J. (2007). Dependency and self-criticism: Relationship with major depressive disorder, severity of depression, and clinical presentation. Depression and Anxiety, 24(8), 586596.

Mundt, J. C., Marks, I. M., Shear, M. K., \& Greist, J. M. (2002). The Work and Social Adjustment Scale: A simple measure of impairment in functioning. The British Journal of Psychiatry, 180(5), 461-464. doi:10.1192/bjp.180.5.461

Muris, P. (2016). A protective factor against mental health problems in youths? A critical note on the assessment of self-compassion. Journal of Child and Family Studies, 25(5), 1461-1465. doi:10.1007/s10826-015-0315-3

Neff, K. D. (2016). The self-compassion scale is a valid and theoretically coherent measure of self-compassion. Mindfulness, 7(1), 264-274. doi:10.1007/s12671-015-0479-3

Pinto-Gouveia, J., Castilho, P., Matos, M., \& Xavier, A. (2013). Centrality of shame memories and psychopathology: The mediator effect of self-criticism. Clinical Psychology: Science and Practice, 20(3), 323-334. doi:10.1111/cpsp.12044

Radloff, L. S. (1977). The CES-D scale: A self-report depression scale for research in the general population. Applied Psychological Measurement, 1(3), 385-401.

Raes, F., Pommier, E., Neff, K. D., \& Van Gucht, D. (2011). Construction and factorial validation of a short form of the Self-Compassion Scale. Clinical Psychology \& Psychotherapy, 18(3), 250-255.

Rosenberg, M. (1986). Conceiving the self. New York: Basic Books.

Shafran, R., Cooper, Z., \& Fairburn, C. G. (2002). Clinical perfectionism: A cognitivebehavioural analysis. Behaviour Research and Therapy, 40(7), 773-791.

Shahar, B., Carlin, E. R., Engle, D. E., Hegde, J., Szepsenwol, O., \& Arkowitz, H. (2012). A pilot investigation of emotion-focused two-chair dialogue intervention for selfcriticism. Clinical Psychology \& Psychotherapy, 19(6), 496-507. doi:10.1002/cpp.762

Shahar, G. (2015). Erosion: The psychopathology of self-criticism. New York, NY, USA: Oxford University Press.

Sheehan, D. V., Lecrubier, Y., Sheehan, K. H., Amorim, P., Janavs, J., Weiller, E., . . . Dunbar, G. C. (1998). The Mini-International Neuropsychiatric Interview (MINI): the development and validation of a structured diagnostic psychiatric interview for DSMIV and ICD-10. Journal of Clinical Psychiatry, 59, 22-33.

Srivastava, A., \& Thomson, S. B. (2009). Framework analysis: a qualitative methodology for applied policy research. Journal of Administration and Governance, 4(2), 72-79.

Tierney, S., \& Fox, J. R. (2010). Living with the anorexic voice: A thematic analysis. Psychology and Psychotherapy: Theory, Research and Practice, 83(3), 243-254. doi:10.1348/147608309X480172

Trapnell, P. D., \& Campbell, J. D. (1999). Private self-consciousness and the five-factor model of personality: Distinguishing rumination from reflection. Journal of Personality and Social Psychology, 76(2), 284.

Verplanken, B., Friborg, O., Wang, C. E., Trafimow, D., \& Woolf, K. (2007). Mental habits: Metacognitive reflection on negative self-thinking. Journal of Personality and Social Psychology, 92(3), 526-541.

Weissman, M. M., Sholomskas, D., Pottenger, M., Prusoff, B. A., \& Locke, B. Z. (1977). Assessing depressive symptoms in five psychiatric populations: A validation study. American Journal of Epidemiology, 106(3), 203-214. 
PHENOMENOLOGY OF SELF-CRITICAL THINKING 


\section{PHENOMENOLOGY OF SELF-CRITICAL THINKING}

Table 1.

Means, Standard Deviations (in brackets), and Results of One-way ANOVA Comparing Questionnaire Scores by Group

\begin{tabular}{|c|c|c|c|c|}
\hline & Control & Depression & $\begin{array}{l}\text { Eating } \\
\text { Disorder }\end{array}$ & ANOVA \\
\hline \multirow[t]{2}{*}{ HINT } & 2.76 & $4.22^{\mathrm{a}}$ & $4.28^{\mathrm{a}}$ & $F(2,75)=64.3, p<.001$ \\
\hline & $(0.65)$ & $(0.48)$ & $(0.49)$ & \\
\hline MPS Negative & 52 & $67^{a}$ & $68^{a}$ & $F(2,75)=7.8, p=.001$ \\
\hline Perfectionism & $(16)$ & $(14)$ & (20) & \\
\hline \multirow[t]{2}{*}{ CES-D } & 11 & $35^{a}$ & $31^{a}$ & $F(2,75)=53.5, p<.001$ \\
\hline & $(7)$ & (9) & (10) & \\
\hline \multirow[t]{2}{*}{ WSAS } & 7 & $23^{\mathrm{a}}$ & $19^{a}$ & $F(2,75)=28.3, p<.001$ \\
\hline & (5) & (9) & (10) & \\
\hline \multirow[t]{2}{*}{ RSE } & 21 & $11^{\mathrm{a}}$ & $10^{\mathrm{a}}$ & $F(2,75)=52.2, p<.001$ \\
\hline & (4) & $(4)$ & $(4)$ & \\
\hline \multirow[t]{2}{*}{$\mathrm{RRQ}$} & 2.41 & $3.35^{\mathrm{a}}$ & $3.17^{a}$ & $F(2,75)=15.6, p<.001$ \\
\hline & $(0.80)$ & $(0.47)$ & $(0.61)$ & \\
\hline \multirow[t]{2}{*}{ SCS } & 3.18 & $2.12^{\mathrm{a}}$ & $1.96^{\mathrm{a}}$ & $F(2,74)=34.0, p<.001$ \\
\hline & $(0.72)$ & $(0.47)$ & $(0.51)$ & \\
\hline \multirow[t]{2}{*}{ FSCRS: IS } & 8 & $18^{\mathrm{a}}$ & $20^{\mathrm{a}}$ & $F(2,75)=47.6, p<.001$ \\
\hline & (5) & (4) & (5) & \\
\hline \multirow[t]{2}{*}{ FSCRS: HS } & 2 & 8 & 11 & $F(2,75)=51.3, p<.001$ \\
\hline & (2) & (4) & (3) & \\
\hline \multirow[t]{2}{*}{ FSCRS: RS } & 21 & $9^{a}$ & $9^{a}$ & $F(2,74)=47.3, p<.001$ \\
\hline & (5) & (5) & (5) & \\
\hline FSCS: Self- & $18^{a}$ & $20^{\mathrm{ab}}$ & $27^{\mathrm{b}}$ & $F(2,75)=4.1, p=.021$ \\
\hline correction & $(12)$ & (11) & $(14)$ & \\
\hline FSCS: Self- & 2 & 10 & 17 & $F(2,75)=29.1, p<.001$ \\
\hline persecution & (3) & (8) & (9) & \\
\hline \multirow[t]{2}{*}{ EDE-Q } & 1.11 & 2.54 & 4.20 & $F(2,75)=49.5, p<.001$ \\
\hline & $(0.97)$ & $(1.38)$ & $(0.98)$ & \\
\hline
\end{tabular}

Note. Values within a row that share a superscript are not significantly different (Post-hoc Tukey HSD). HINT= Habit Index of Negative Thinking; MPS = Multidimensional Perfectionism Scale; CES-D= Centre for

Epidemiological Studies Depression Scale; WSAS = Work and Social Adjustment Scale; RSE= Rosenberg SelfEsteem scale; RRQ= Rumination Responses Questionnaire; SCS= Self-compassion scale; FSCRS= Forms of Self Criticizing/attacking and reassurance scale; IS= Inadequate Self subscale; HS= Hated Self subscale; RS= Reassured Self subscale; FSCS = Functions of Self-Criticizing/attacking scale; EDE-Q = Eating Disorder Examination Questionnaire. 
PHENOMENOLOGY OF SELF-CRITICAL THINKING

Table 2.

Pearson Correlation Coefficients for the Questionnaire Measures

\begin{tabular}{lllllllllll}
\hline HINT & MPS & RSE & RRQ & SCS & & & FSCRS & & CES- \\
\cline { 5 - 7 } & Neg & & & & IS & HS & RS & D \\
\hline
\end{tabular}

\begin{tabular}{lcccccccccc}
\hline HINT & - & & & & & & & \\
MPS Neg & $.444^{*}$ & - & & & & & & \\
RSE & & $-.858^{*}$ & $-.553^{*}$ & - & & & & & \\
RRQ & & $.714^{*}$ & $.347^{*}$ & $-.685^{*}$ & - & & & & \\
SCS & & $-.810^{*}$ & $-.569^{*}$ & $.769^{*}$ & $-.733^{*}$ & - & & & \\
FSCRS & IS & $.839^{*}$ & $.497^{*}$ & $-.844^{*}$ & $.723^{*}$ & $-.825^{*}$ & - & & \\
& HS & $.758^{*}$ & $.304^{*}$ & $-.721^{*}$ & $.549^{*}$ & $-.654^{*}$ & $.735^{*}$ & - & \\
& RS & $-.755^{*}$ & $-.502^{*}$ & $.815^{*}$ & $-.599^{*}$ & $.793^{*}$ & $-.731^{*}$ & $-.645^{*}$ & - \\
& & & & & & & & \\
CES-D & & $.816^{*}$ & $.463^{*}$ & $-.804^{*}$ & $.603^{*}$ & $-.685^{*}$ & $.746^{*}$ & $.721^{*}$ & $-.736^{*}$ & -
\end{tabular}

Note. HINT= Habit Index of Negative Thinking; MPS Neg= Negative Perfectionism subscale of Multidimensional Perfectionism Scale; RSE= Rosenberg Self-Esteem scale; RRQ= Rumination Responses Questionnaire; $S C S=$ Self-compassion scale; FSCRS= Forms of Self Criticizing/attacking and reassurance scale; IS= Inadequate Self subscale; HS= Hated Self subscale; RS= Reassured Self subscale; CES-D= Centre for Epidemiological Studies Depression Scale.

${ }^{*} p<.05$ 
PHENOMENOLOGY OF SELF-CRITICAL THINKING

Table 3.

Means, Standard Deviations (in Brackets), and Results of One-way ANOVA of Beliefs About Self-Critical Thinking, by Group

\begin{tabular}{|c|c|c|c|c|}
\hline & Control & Depression & $\begin{array}{l}\text { Eating } \\
\text { Disorder }\end{array}$ & ANOVA \\
\hline $\begin{array}{l}\text { Controllability of } \\
\text { self-critical thinking } \\
(0-10)\end{array}$ & $\begin{array}{c}7.3 \\
(1.9)\end{array}$ & $\begin{array}{l}2.8^{\mathrm{a}} \\
(1.9)\end{array}$ & $\begin{array}{c}2.7^{a} \\
(1.6)\end{array}$ & $F(2,58)=29.4, p<.001$ \\
\hline $\begin{array}{l}\text { Desire to change } \\
\text { self-critical thinking } \\
(0-10)\end{array}$ & $\begin{array}{c}4.5 \\
(2.9)\end{array}$ & $\begin{array}{c}8.4 \\
(1.7)\end{array}$ & $\begin{array}{l}6.8 \\
(2.3)\end{array}$ & $F(2,60)=13.5, p<.001$ \\
\hline $\begin{array}{l}\text { Self-critical thinking } \\
\text { has benefits for me } \\
(1-7)\end{array}$ & $\begin{array}{l}2.7^{\mathrm{a}} \\
(1.2)\end{array}$ & $\begin{array}{c}4.9 \\
(1.5)\end{array}$ & $\begin{array}{l}3.5^{\mathrm{a}} \\
(1.6)\end{array}$ & $F(2,75)=16.7, p<.001$ \\
\hline $\begin{array}{l}\text { Self-critical thinking } \\
\text { has disadvantages } \\
\text { for me } \\
(1-7)\end{array}$ & $\begin{array}{c}3.3 \\
(1.4)\end{array}$ & $\begin{array}{l}1.9^{\mathrm{a}} \\
(1.0)\end{array}$ & $\begin{array}{l}1.8^{\mathrm{a}} \\
(1.0)\end{array}$ & $F(2,75)=12.2, p<.001$ \\
\hline $\begin{array}{l}\text { I would like to } \\
\text { reduce my self- } \\
\text { criticism } \\
(1-7)\end{array}$ & $\begin{array}{c}3.5 \\
(1.4)\end{array}$ & $\begin{array}{l}1.6^{\mathrm{a}} \\
(0.9)\end{array}$ & $\begin{array}{l}2.0^{\mathrm{a}} \\
(1.2)\end{array}$ & $F(2,75)=18.6, p<.001$ \\
\hline $\begin{array}{l}\text { Being self-critical is } \\
\text { part of my } \\
\text { personality } \\
(1-7)\end{array}$ & $\begin{array}{l}3.3^{\mathrm{a}} \\
(1.7)\end{array}$ & $\begin{array}{l}3.0^{\mathrm{a}} \\
(2.0)\end{array}$ & $\begin{array}{c}1.9 \\
(0.8)\end{array}$ & $F(2,75)=5.2, p=.007$ \\
\hline $\begin{array}{l}\text { My self-criticism is a } \\
\text { learnt habit that } \\
\text { could be unlearnt } \\
(1-7)\end{array}$ & $\begin{array}{c}4.2 \\
(1.7)\end{array}$ & $\begin{array}{l}2.8^{a} \\
(1.2)\end{array}$ & $\begin{array}{l}3.2^{\mathrm{a}} \\
(1.1)\end{array}$ & $F(2,75)=7.6, p=.001$ \\
\hline $\begin{array}{l}\text { It would be difficult } \\
\text { to reduce my self- } \\
\text { criticism (1-7) }\end{array}$ & $\begin{array}{c}3.3 \\
(1.6)\end{array}$ & $\begin{array}{l}2.4^{\mathrm{a}} \\
(1.2)\end{array}$ & $\begin{array}{l}1.7^{\mathrm{a}} \\
(0.6)\end{array}$ & $F(2,75)=12.2, p<.001$ \\
\hline $\begin{array}{l}\text { I would be } \\
\text { interested in advice } \\
\text { about how to reduce } \\
\text { my self-criticism } \\
(1-7)\end{array}$ & $\begin{array}{c}3.5 \\
(1.5)\end{array}$ & $\begin{array}{l}1.3^{\mathrm{a}} \\
(0.5)\end{array}$ & $\begin{array}{l}1.8^{a} \\
(1.1)\end{array}$ & $F(2,74)=28.9, p<.001$ \\
\hline
\end{tabular}

